Editorial

\title{
Safe anaesthesia in remote sites
}

\section{Editorial}

Contemporary practice of anaesthesia includes knowledge and skills on perioperative care, anaesthesia, pain management, intensive care medicine, emergency medicine and prehospital care. These activities are precise efforts to develop patient safety. The practice of modern anaesthesia in most hospitals around the urbane world is claimed to be safer than ever. Since the first public demonstration of general anaesthesia by William Morton, and later the invention of spinal anaesthesia by August Bier, there have been countless advances in this specialty. Because of such dramatic anaesthesia advances, nowadays surgeons of all specialties are able to cure most patients that need difficult interventions; they can dissect safely each area of the human body to remove the ills that affect each patient. Currently we have a pharmaceutical armamentarium that facilitate safer anaesthesia induction and maintenance, as well as drugs to reverse some pharmacological effects of the medicines used in anaesthesia and related fields. There are new analgesics and we know how to use old drugs as analgesics or adjuvants to prevent and treat acute and chronic pain. The availability of state of the art anaesthesia equipment allowed us to monitor all the vital signs and specific body functions like oximetry, capnography, ventilatory parameters, cardiac performance, brain activity, muscle relaxation, etc. As anesthesiologists, we are able to recognize, to change, and to correct each monitored parameters according to patient and surgeon needs.

There are several organizations that have elaborated guidelines to assure the best anaesthesia care. In Europe those standards are included in the Helsinki declaration on patient safety in an aesthesiology. ${ }^{1-4}$ In the USA the American Association of Anesthesiologists (ASA) had developed standards and guidelines for a better practice of all anaesthesia areas. ${ }^{5}$ The World Federation of Societies of Anesthesiologists (WFSA) has a Task Force on Anaesthesia Safety that developed standards for safe anaesthesia according with the core components of the WHO global initiative "Safe Surgery Saves Lives" for patient safety. The WFSA guides were planned to give guidance and assistance to anaesthesiologists, anaesthesia organizations, hospitals, and governments to successful provide qualified and safe anaesthesia care. ${ }^{6}$ In Latin America the Confederación Latinoamericana de Sociedades de Anestesiología has published its recommendations, which are quite similar to most recommended guidelines. Most countries around the globe have written standards for safe anesthesia.

These national and international guidelines have improved to save lives, but unfortunately are not applicable in most remote places because in those locations there are not enough resources to adhere to its recommendations, making almost impossible to use advanced technology. Even in many countries with acceptable gross domestic product (GDP) there are hospitals with very few resources to practice safe anaesthesia. Other scenarios that hinder safe anaesthesia are the battlefields and areas of natural disasters such as earthquakes, tsunamis, and hurricanes to name a few.

In a place where the blood contained in the pleural cavity after a traumatic hemothorax is collected in urine plastic bags and infused

\author{
Víctor Whizar-Lugo,' Carlos Cortes-Gómez ${ }^{2}$ \\ 'ACCOA Chief Editor, Intensive Care Unit, Hospital General de \\ Tijuana, México \\ ${ }^{2}$ Anaesthesiologist, International Committe of the Red Cross, \\ Switzerland
}

Correspondence: Víctor Whizar-Lugo, Intensive Care Unit, Hospital General de Tijuana, ISESALUD Av. Centenario I085I, Zona Rio, Tijuana B.C., México, Tel +52664-6848905, Fax +52664-6848906, Email vwhizar@anestesia-dolor.org

Received: October 20,2015 | Published: October 24, 2015

back to the patient there are no practical guidelines to solve the life threaten issues. The surgical team has to act according with what they have and they know. In these sorts of scenarios two unresolved questions arise: It is a need to have a guide document in remote places without enough resources to practice safe anaesthesia? What is the extreme minimum to do so? For those remote sites it is a must to have at least a check list that includes -We believe- safety rules, equipment, drugs and personnel to provide a "safe surgical room" to assure that the surgeons can operate under "safe anaesthesia technique". The WHO surgical checklist published in $2009^{7}$-when properly appliedhelp to generate important difference in the patient safety, but requires leadership, flexibility, and a dedicated team work in order to benefit patients all over the globe. ${ }^{8,9}$

Moreover, the availability of medical personnel is poor in many low and middle income countries. Interesting data collected by Hoyler et al. ${ }^{10}$ in 57 countries considered by the WHO as health workforce crisis showed that there were no data in 23 countries and only six countries have comprehensive information. Besides lack of surgeons and obstetricians, these authors found that anesthesiologist density ranged from 0 to 4.9 per 100,000 people. Total anaesthesiologist, obstetrician, and surgeon density was significantly correlated with GDP per capita $(\mathrm{r}(2)=0.097, \mathrm{p}=0.0002)$. This is a factor that negatively impacts on maternal mortality. Two studies done in Uganda ${ }^{11,12}$ found shortage of fundamental human resources and infrastructure to deliver suitable health care, including surgery and anaesthesia at many government hospitals; 0.2 major operating theater per 100,000 people, no pediatric surgeons, 0.7 accredited general surgeons and 1.1 accredited anaesthesiologists per 100,000 population, and more an aesthetists were no physicians. Beside the shortness of medical personnel, hospitals in the poorest countries of the world frequently suffer interruption of electricity, oxygen, and water supplies; conditions that makes health care unsafe. This scenario also happens in developed geographical areas under the consequences of severe destruction due to the effects of natural disasters or war devastation. Fortunately, there are groups that have developed reliable anaesthesia 
equipment to be used in these types of circumstances. This kind of anaesthesia machines function with no electricity and no cylinder of compressed gases supply. These non-expensive anaesthesia machines are much less complex than the standard equipment. It combines a draw over anaesthesia system with an oxygen concentrator and a gas-driven ventilator. ${ }^{13-17}$ It is a fact that sophisticated and expensive anaesthesia equipment is not useful in these circumstances, so designers of anaesthesia machines and additional equipment to be used in remote sites must take into consideration that local conditions might be deficient, shortness of oxygen and electricity, as well as lack of maintenance personnel. Ideally, global norms should encourage the design of suitable equipment to guarantee safe anaesthesia worldwide. $^{16}$

Sometimes deficiencies favor unimaginable develops medical skills that are useful at remote sites. Many of these patients are managed with loco regional anesthesia, i.v. or i.m. ketamine, ventilating the patients with ambient air delivered by an ambubag. ${ }^{21}$ The current tendency to restrict the use of ketamine ${ }^{22}$ is a serious harm for these patients. Figure 1 shows one of those remote sites where anaesthesia is practiced as safe as possible with the limited resources available.

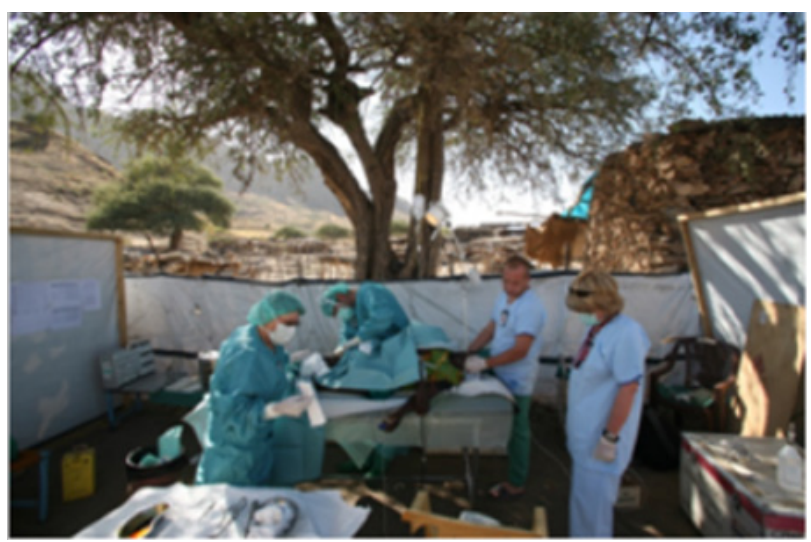

Figure I International Committee Red Cross surgical team working in a victim patient during a civil war in Africa. Notice the improvised operating room and qualify medical personal saving lives with almost no equipment.

Non-government organizations (NGO) have initiatives to create safe anaesthesia for remote areas as part of their main goals; the International Red Cross, WFSA, Safe Anesthesia Worldwide,(http:// www.safe4all.org.uk/), the Lancet Commission on Global Surgery (http://www.lancetglobalsurgery.org/), the Sphere Project (http:// www.sphereproject.org/)justto mention a few, that have developed special medical groups to support mankind suffering from natural disasters like earthquakes, hurricanes, tsunamis, volcano eruptions, and war conflicts. ${ }^{23,24}$

The effortless to continuous updating through Internet allows us to refurbish our knowledge and skills that directly benefit our patients. This free avalanche of new knowledge easier to implement new ways of medical management. Little or no availability of the internet in these sites in conflict makes it difficult for medical personnel to be updated using this way, so it is a must to create programs that facilitate deliveries to remote sites hoping to be accessible on the WEB. ${ }^{25}$

Unfortunately, there are millions of remote places around the world were anaesthesia advances are not accessible on everyday basis, not even for special occasions. Natural disasters, war situations, geopolitical circumstances, ignorance, extreme poverty are some of the discussed contexts that alone or combined, are responsible of the unsafe medical care of millions of human beings that will died irremediably. There are few governments and NGO that being aware of this problem, had engaged in actions to reduce this awkward situation.

To end this editorial, it is worth to mention that colleagues attending humanitarian task, giving and teaching safe anaesthesia in remote locations should prepare their self physically and emotionally to stressful situations, and above all, take care of their physical integrity. ${ }^{26,27}$

\section{Conflicts of Interest}

The authors do not have any Conflict of interests.

\section{Acknowledgments}

None.

\section{Funding}

None.

\section{References}

1. Mellin-Olsen J, Staender S, Whitaker DK, et al. The Helsinki declaration on patient safety in anaesthesiology. Eur J Anaesthesiol. 2010;27(7):592-597.

2. Whitaker DK, Brattebø G, Smith AF, et al. The Helsinki declaration on patient safety in anaesthesiology: putting words into practice. Best Pract Res Clin Anaesthesiol. 2011;25(2):277-290.

3. Staender S, Smith A, Brattebø G, et al. Three years after the launch of the Helsinki declaration on patient safety in anaesthesiology: the history, the progress and quite a few challenges for the future. Eur J Anaesthesiol. 2013;30(11):651-654.

4. Wulf H. Patient safety in anaesthesiology: implementation of the declaration of Helsinki. Anasthesiol Intensivmed Notfallmed Schmerzther. 2013;48(1): 1 .

5. ASA Standards \& Guidelines.

6. International Task Force on Anesthesia Safety. The 2008 international standards for a safe practice of anesthesia. Anesteziol Reanimatol. 2009;(6):4-10.

7. WHO Guidelines for Safe Surgery. 2009.

8. Treadwell JR, Lucas S, Tsou AY. Surgical checklists: a systematic review of impacts and implementation. BMJ Qual Saf. 2014;23(4):299-318.

9. Walker IA, Reshamwalla S, Wilson IH. Surgical safety checklists: do they improve outcomes? Br J Anaesth. 2012;109(1): 47-54.

10. Hoyler M, Finlayson SR, McClain CD, et al. Shortage of doctors, shortage of data: a review of the global surgery, obstetrics, and anesthesia workforce literature. World J Surg. 2014;38(2):269-280.

11. Walker IA, Obua AD, Mouton F, et al. Paediatric surgery and anaesthesia in south-western Uganda: a cross-sectional survey. Bull World Health Organ. 2010;88(12):897-906.

12. Linden AF, Sekidde FS, Galukande M, et al. Challenges of surgery in developing countries: a survey of surgical and anesthesia capacity in Uganda's public hospitals. World J Surg. 2012;36(5):1056-1065.

13. Eltringham RJ, Varvinski A. The Oxyvent. An anaesthetic machine designed to be used in developing countries and difficult situations. Anaesthesia. 1997;52(7):668-672.

14. Bailey TM, Webster S, Tully R, et al. An assessment of the efficiency of the Glostavent ventilator. Anaesthesia. 2009;64(8):899-902. 
15. Eltringham RJ, Neighbour RC. The environmental impact of the Glostavent ${ }^{\circledR}$ anesthetic machine. Anesth Analg 2015;120(6):1264-1270.

16. McCormick BA, Eltringham RJ. Anaesthesia equipment for resourcepoor environments. Anaesthesia. 2007;62 Suppl 1: 54-60.

17. Tully R, Eltringham R, Walker IA, et al. The portable Glostavent: a new anaesthetic machine for use in difficult situations. Anaesth Intensive Care. 2010;38(6):1085-1089.

18. Merry AF, Eichhorn JH, Wilson IH. Extending the WHO 'Safe Surgery Saves Lives' project through Global Oximetry. Anaesthesia. 2009;64(10):1045-1048.

19. Walker IA, Merry AF, Wilson IH, et al. Global oximetryoximetry: an international anaesthesia quality improvement project. Anaesthesia. 2009;64(10):1051-1060.

20. Finch LC, Kim RY, Ttendo S, et al. Evaluation of a large-scale donation of Life box pulse oximeters to non-physician anaesthetists in Uganda. Anaesthesia. 2014;69(5):445-451.

21. Pesonen P. Pulse oximetry during ketamine anaesthesia in war conditions. Can J Anaesth. 1991;38(5):592-594.
22. Dong TT, Mellin-Olsen J, Gelb AW. Ketamine: a growing global health-care need. Br J Anaesth. 2015;115(4):491-493.

23. Froese A. Anesthesia and the role of short-term service delivery in developing countries. Can J Anaesth. 2007;54(11):940-946.

24. Wilson IH, Walker IA (2015) Global surgery and anesthesia: No longer a pipe dream. Anesth Analg. 2015;121(4):841-842.

25. Whizar-Lugo V, Hernández-Cortez E, Flores-Carrillo JC, et al. Continuous updating in anesthesia and related sciences: an internet free project. Brit J Anaesth. 2012;108:(S2)ii181.

26. Dahlgren AL, Deroo L, Avril J, et al. Health risks and risk-taking behaviors among International Committee of the Red Cross (ICRC) expatriates returning from humanitarian missions. $J$ Travel Med. 2009;16(6):382-390.

27. Stoney RJ, Jentes ES, Sotir MJ, et al. Pre-travel preparation of US travelers going abroad to provide humanitarian service, Global TravEpiNet 2009-2011. Am J Trop Med Hyg. 2014;90(3):553-559. 